\title{
Effect of multiple subconjunctival conbercept injections as an adjuvant to the surgical treatment of pterygium: a prospective randomised comparative 6-month follow-up study
}

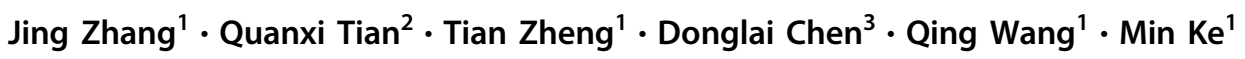

Received: 15 February 2019 / Revised: 12 June 2019 / Accepted: 22 August 2019 / Published online: 25 September 2019

(c) The Author(s), under exclusive licence to The Royal College of Ophthalmologists 2019

\begin{abstract}
Objective To evaluate the safety and efficacy of multiple subconjunctival injections of conbercept for pterygium patients after surgery.

Methods As a prospective randomised interventional trial, 96 eyes from 96 patients with a tendency to recur were collected and divided randomly into conbercept and 5-fluorouracil groups on the 5th day after pterygium. All patients received three subconjunctival injections of conbercept $(0.2 \mathrm{ml})$ or 5 -fluorouracil $(0.2 \mathrm{ml})$ on the 5 th day (baseline), and 2 and 4 weeks postoperatively. The pterygium morphology, colour intensity, recurrence, and complications were recorded and analysed pre-1st injection and 1 day, 1 week, 1 month, 3 months, and 6 months post-3rd injection. Moreover, no patient was drop-out.

Results There were striking differences between the two groups on post-3rd injections 1 day, 1 week, 1 month, 3 months, and 6 months $(p=0.001,0.002,0.000,0.000$, and 0.002 , respectively) with respect to colour intensity: the eyes in conbercept group were lighter than the 5-Fu group. On post-3rd injection 6 months, prominent disparities existed between the two groups with respect to pterygium morphology $(p=0.006)$ and recurrence $(p=0.002)$, occurred in the conbercept group prior to the 5-Fu group. Moreover, corneal abrasions were not noted in the conbercept group, which was significantly less than the 5 -Fu group $(17 / 48 ; p=0.000)$. There was no conspicuous discrepancy between the two groups with respect to subconjunctival haemorrhage $(p=0.789)$ and persistent epithelial defects $(p=0.078)$.

Conclusion Multiple subconjunctival conbercept injections as an adjunct therapy for pterygium surgery was shown to be safe, effective, and well-tolerated.
\end{abstract}

\section{Introduction}

Pterygium is an ocular surface disease that is characterised by invasion of awning-shaped proliferation of fibrovascular tissue from the bulbar conjunctiva to the cornea. Currently, the main treatment strategy of pterygium is surgery; however, the problem of post-operative recurrence has not

$\triangle \operatorname{Min} \mathrm{Ke}$

keminyk@163.com

1 Department of Ophthalmology, Zhongnan Hospital of Wuhan University, No 169. Donghu Road, 430071 Wuhan, Hubei, China

2 School of Information Management and statistics, Hubei University of Economics, No. 8 Yangqiaohu Road, 430205 Wuhan, Hubei, China

3 Department of Ophthalmology, The Second People's Hospital of Honghu, No 142. Xinjian Road, 433202 Honghu, Hubei, China been resolved. Preventing recurrences has always been the focal goal of surgery. Although the pathogenesis underlying pterygium recurrence is not fully clarified, fibrovascular proliferation and angiogenesis have been reported to be important factors. Therefore, it is well-known that there are several common methods, such as adjuvant anti-metabolic treatments, including mitomycin, 5-fluorouracil (5-Fu), and corticosteroids, to prevent recurrences [1]. An increased incidence of adverse effects following anti-metabolic treatment has been observed, including corneal abrasions, corneal epithelial defects, subconjunctival haemorrhage, aseptic scleritis, and infections [2]. Therefore, a safe and effective agent is urgently needed to prevent recurrences after pterygium surgery.

Vascular endothelial growth factor (VEGF) has been detected in primary and recurrent pterygium [3]. It is well-known that anti-VEGF antibodies with antiproliferative and anti-angionenesis activities [4, 5] are associated with a more precise effect of inhibiting 
recurrences after surgery and fewer adverse effects than anti-metabolic drugs.

Conbercept is the newest and first independently developed anti-VEGF antibody and recombinant fusion protein developed in China [6]. Conbercept has the advantages of more targets, stronger affinity, and lower price than a monoclonal antibody, like bevacizumab and ranibizumab. Currently, no research has reported the prevention of recurrences after pterygium surgery by conbercept. Therefore, our team designed this study to evaluate the safety and efficacy of multiple subconjunctival conbercept injections for pterygium patients after surgery by observing pterygium morphology, colour intensity, recurrence, and complications.

\section{Subjects and methods}

A prospective, randomised interventional trial was conducted. All subjects with primary and recurrent pterygia who underwent simple excision or conjunctiva autograft surgery were informed and consented to participate voluntarily in this study in accordance with the institutional guidelines. Institutional Review Board Approval was obtained from Zhongnan Hospital of Wuhan University in Wuhan, Hubei Province, in China. All participants adhered to the tenets of the Declaration of Helsinki. The subjects could withdraw from the study for any reason at any time without providing a reason. Subsequent medical treatment and the physician-patient relationship was not affected after study withdrawal.

Sample size was calculated from proportions with assumption of success rate of about $80 \%$ for $5-\mathrm{Fu}$ and conbercept with surgeries, including simple excision or conjunctiva autograft surgery, alpha error, $0.05 \%$ and a power of $90 \%, \quad N=\frac{\mathrm{Za} / \mathrm{PO}(1-\mathrm{P} 0)-\mathrm{Zb} / \mathrm{P} 1(1-\mathrm{P} 1)^{2}}{\mathrm{P} 1-\mathrm{P} 0}=70 \quad[7]$. Moreover, combining with our team's capability of taking pterygium patients, the size was estimated as 96 . Ninety-six patients underwent pterygium surgeries, which were precisely performed under the same microscope by the same surgeon (MK) totally blinded and included 96 eyes. The patients were both genders and ranged from 45 to 80 years of age. The patients were recruited from the Ophthalmology department in Zhongnan Hospital of Wuhan University in Wuhan, between 1 September, 2017 and 31 August, 2018, and randomly divided into conbercept and 5-Fu groups according to stratified blocked randomisation using a random numbers table (by JZ). If both eyes were eligible, only the more severe eye was included.

\section{The basal time was the 5th day after surgery}

The inclusion criteria were subjects with fine episcleral vessels without fibrous tissue in the surgical areas or more severe according to recurrent grades [8] on the 5th day after surgery.

The exclusion criteria were as follows: 1. other ocular disease, such as keratoconus, pseudopterygium, blepharitis, crystal dislocation, glaucoma, shallow anterior chamber, uveitis, retinal diseases, congenital anomalies, nasolacrimal duct obstruction, ocular trauma, or autoimmune diseases; 2 . allergic to conbercept; 3 . uncontrolled diabetes or hypertension, and other medical conditions increasing the risk of complications for surgery; 4. pregnancy or lactating women; and 5. unable to accept subsequent review on schedule.

The conbercept group comprises subjects who were injected with $0.2 \mathrm{ml}$ of conbercept (Conbercept Ophthalmic Injection, Chengdu Kanghong Biotechnologies Co. Ltd, $10 \mathrm{mg} / \mathrm{ml}, 0.2 \mathrm{ml}$ ) three times (at baseline, and 2 and 4 weeks) in the area of the most obvious conjunctiva hyperaemia with a 29-gauge needle on a 1-ml syringe (Ultra-Fine ${ }^{\circledR}$ insulin syringe, $1 \mathrm{ml} 29 \mathrm{G} \times 1 / 2$; Becton Dickinson and Company, Franklin Lakes, New Jersey, USA) (by TZ).

The 5-Fu group was comprised of subjects who were injected with $0.2 \mathrm{ml}$ of 5-Fu (fluorouracil injection, $10 \mathrm{ml}$ [0.25 g]; Tianjin Jin Yao Amino Acid Co. Ltd, Tianjin, China) at the same times and locations, and using the same needles as the conbercept group (by TZ).

All patients were examined routinely by the same totally blinded examiner $(\mathrm{QW})$ on pre-1st injection and post-3rd injection 1 day, 1 week, 1 month, 3 months, and 6 months, as follows: corrected distance visual acuity with Snellen's chart (Sanke SL-II, YZB/gui0195-2004; Sanke Medical Co. Ltd, Nanning, China); anterior segment examination with slit-lamp biomicroscopy (66VT YZ5FI, YZB/su 0311 2014; 66 VISION TECH Co. Ltd, Suzhou, China); IOP measurement with a Goldmann applanation tonometer (AT900 ; Hagg-Streit AG, Koniz, Switzerland) (calibrated monthly); and direct fundoscopy (66VT YZ6E, 66 VISION TECH Co. Ltd, Suzhou, China). For this analysis, the pterygium morphology, colour intensity, recurrence morphology, and complication were recorded by the same investigator (DLC) totally blinded. Furthermore, follow-up visits were 6 months.

Pterygium morphology was graded according to Tan's scheme [9]. Tan's scheme has been previously described and validated as a marker of severity. The pterygia were classified into grades 1,2 , or 3 based on slit-lamp biomicroscopy evaluation, as follows: $1=$ grade 1 ("atrophic"), clearly visible episcleral vessels under the body of the pterygium; $2=$ grade 2 ("intermediate"), partially visible episcleral vessels under the body of the pterygium; and $3=$ grade 3 ("fleshy"), totally obscured episcleral vessels underlying the body of the pterygium.

Grading of colour intensity was on a scale of $0-4$ according to Teng [10], as follows: $0=$ unremarkable; $1=$ trace; $2=$ mild; $3=$ moderate; and $4=$ diffuse. 
Evidence of recurrence by appearance of the surgical bed on post-3rd injection 6 months was noted according to Prabhasawat's criteria [8], as follows: $1=$ grade I, normal appearance; $2=$ grade II, fine episcleral vessels without corneal extension; $3=$ grade III, episcleral vessels and fibrovascular tissue without corneal extension; and $4=$ grade IV, fibrovascular tissue extending past the limbus.

Complications were recorded, including corneal abrasions, corneal epithelial defects, subconjunctival haemorrhage, aseptic scleritis, and infections.

\section{Statistical analysis}

The data analysis was performed using SPSS software (version 20.0; SPSS, Inc., Chicago, IL, USA) (blinded by QXT). Independent sample $t$-tests were used to evaluate measurement data between two groups. Proportion data were analysed by Pearson $\chi 2$ test. Ranked data were analysed by non-parametric tests (Mann-Whitney $U$-test). A $p$-value $\leq 0.05$ was considered statistically significant.

\section{Results}

The baseline characteristics for all subjects are shown in Table 1. There was no significant difference in statistics between the two groups with respect to baseline characteristics. All patients were Han ethnicity. Moreover, no patient was lost to follow-up.

Pterygium morphology is measured and graded, as shown in Table 2. On the post-3rd-injection 6 months, there was significant difference on pterygium morphology between the two groups ( $p=0.006)$. However, conspicuous discrepancy was not detected between them on the other viewing times.

Grading of colour intensity is shown in Table 3. For the colour intensity, striking differences were observed on post3rd-injection 1 day, 1 week, 1,3 and 6 months $(p=0.001$, $0.002,0.000,0.000,0.002)$ between the two groups.

Evidence of recurrence by appearance of surgical bed at 6 months was noted in Table 4. Statistical difference was observed on post-3rd-injection 6 months $(p=0.002)$ between the two groups. In fact, clinical recurrence that need to be treat was grade IV (Table 5).
On post-3rd-injection 6 months, the number of cases of recurrence of simple excision and conjunctiva autograft surgery in conbercept group were 0 , hence the recurrent rates of the two surgeries were $0 \%$. Meanwhile, in 5-Fu group at the same time, four patients received simple excision surgery and two patients received conjunctiva autograft surgery had recurrence, hence the recurrent rates were $20 \%$ and $7.1 \%$, respectively. In every subgroup of simple excision surgery, conjunctiva autograft surgery and total, $95 \%$ confidence interval (CI) of relative risk (RR) were infinite because the number of cases of recurrence in conbercept group were 0 . Compared with in 5-Fu group, the recurrence rates in conbercept group were significantly less in simple excision surgery (ARR, 0.20; 95\% CI, 0.0248 to 0.375 ) and total (absolute risk reduction (ARR), 0.125; 95\% CI, 0.0314 to $0.219 ; p=0.0265<0.05$ ) because the values of the upper and lower limit were $>0$.

Complications in both the groups were recorded on the post-3rd-injection 6 months in Table 6. Corneal abrasion was not detected in the conbercept group, which was significantly less than the 5-Fu group (17 eyes) $\left(\chi^{2}=20.658\right.$ $p=0.000)$. Moreover, only three eyes of persistent epithelial defect were surveyed in 5-Fu group, and none in conbercept group $\left(\chi^{2}=3.097, p=0.078\right)$. Similarly, there was no conspicuousness diversity in the observation of subconjunctival haemorrhage, including nine eyes in conbercept group and eight eyes in 5-Fu group $\left(\chi^{2}=0.071\right.$, $p=0.789)$. No patient had undergone aseptic scleritis and infection in both groups.

\section{Discussion}

Some factors, such as age, ultraviolet exposure, dust, a hot and dry environment, and operative method and skill, are related to pterygium recurrence [11]. Although there are many studies discussing how to reduce the recurrence rate after surgery, the effect has been unsatisfactory. Indeed, more serious side effects following several widely used adjuvant therapy methods have been reported [2, 8].

The mechanism of recurrence after pterygium surgery [12, 13] may be that the operative wound and inflammation activates the proliferation of fibroblasts and neovascularization, and the deposition of extracellular
Table 1 Demographic and baseline characteristics of patients

\begin{tabular}{lllll}
\hline & Conbercept group & 5-Fu group & & $p$ \\
\hline No. of patients (case) & 48 & 48 & & \\
Mean age \pm SD (years) & $60.125 \pm 8.843$ & $61.021 \pm 7.969$ & $t=-0.521$ & 0.603 \\
Male/female (case) & $20 / 28$ & $24 / 24$ & $\chi^{2}=0.671$ & 0.413 \\
Right/left (case) & $22 / 26$ & $26 / 22$ & $\chi^{2}=0.667$ & 0.414 \\
Excision/autograft (case) & $18 / 30$ & $20 / 28$ & $\chi^{2}=0.174$ & 0.676 \\
\hline
\end{tabular}




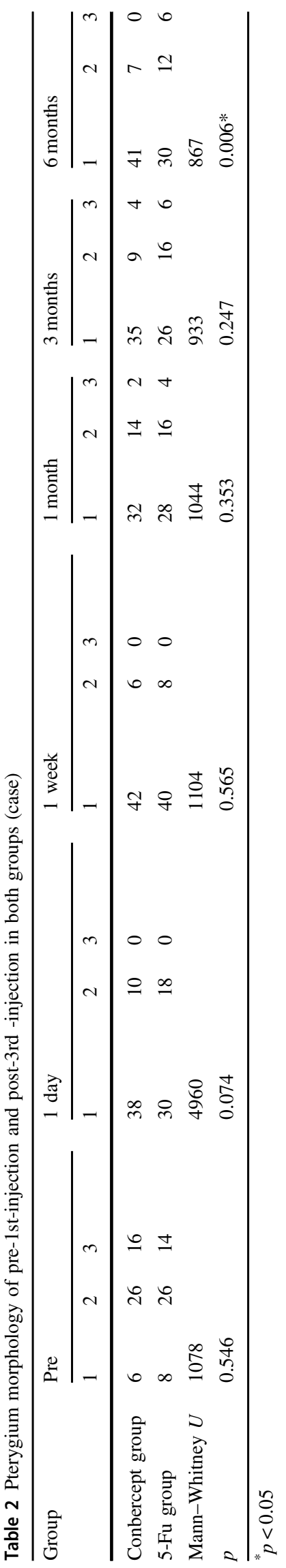

matrix. Recurrence in the cornea may facilitate the robust growth response of fibre blood vessels [14]. Therefore, reducing the proliferation of fibroblasts and neovascularization could inhibit the recurrence of pterygium.

A large number of proliferating fibroblasts exist in the pathologic findings of pterygium. It has been reported [15] that VEGF enhances proliferation in human fibroblasts of the pterygium and promotes the appearance of angiogenesis mimicry. Moreover, the quantity of VEGF in recurrent pterygium is greater than in primary pterygium, which is greater than normal conjunctival [16]. There is more proliferation of fibroblasts, fainter basal cell boundaries and more significant neovascularization in the stroma of recurrent pterygium. Hence, anti-VEGF treatment might be more effective in recurrent pterygium, especially if the treatment begins before neovascularization is established.

Some studies [7, 17-25] have involved the application of bevacizumab and ranibizumab in the prevention of pterygium recurrence; however, the method, time, frequency, and dosing were not uniform.

The method of dosing was as follows. Wu et al. [17] observed that the phenomenon of significant vascular regression was recorded in patients with recurrent pterygium after application of bevacizumab drops. Motarjemizadeh et al. [18] reported that the recurrence rate was not observed in patients who applied bevacizumab drops (10 $\mathrm{mg} / \mathrm{ml}$ ), and $13.3 \%$ and $46.7 \%$ in patients who applied bevacizumab $(5 \mathrm{mg} / \mathrm{ml})$ and placebo drops, respectively. The difference was significant between the former and the latter two treatments; however, in most other studies antiVEGF drugs have been used in subconjunctival injections [19]. The method of subconjunctival injection was selected in this study because it is difficult to meet the demand with drops and the preservation of anti-VEGF drugs requires cold storage.

The time of dosing was as follows. Alsmman et al. [20] recognised that there was a decrease in pterygium epithelial cells, degeneration and apoptosis of stromal fibres, deformation and degradation of glial and elastic fibres, and destruction of capillaries in patients who accepted subconjunctival injection of bevacizumab before pterygium excision (1 month). Bekibele et al. [7] showed that there was no significant difference in the success and recurrence rates between the subconjunctival injections of bevacizumab and 5-Fu during autologous conjunctival transplantation. Nuzzi et al. [21] found that there was a significantly lower recurrent rate after 6 months of subconjunctival bevacizumab injections on pre- and post-operative primary pterygium excision than in the control group. Our team chose the post-operative 5 days after surgery as the time of subconjunctival injection to prevent recurrence because the post-operative $3-5$ days was the time of maximum proliferation of subconjunctival fibroblasts in histologic studies [22]. 
Table 3 Colour intensity of pre-1st-injection and post-3rd-injection in both the groups (case)

\begin{tabular}{|c|c|c|c|c|c|c|c|c|c|c|c|c|c|c|c|c|c|c|c|c|c|c|c|c|c|c|c|c|}
\hline \multirow[t]{2}{*}{ Group } & \multicolumn{4}{|l|}{ Pre } & \multicolumn{5}{|c|}{1 day } & \multicolumn{4}{|l|}{1 week } & \multicolumn{5}{|c|}{1 month } & \multicolumn{5}{|c|}{3 months } & \multicolumn{5}{|c|}{6 months } \\
\hline & 0 & 2 & 3 & 4 & 0 & 1 & 2 & 3 & 4 & 0 & 2 & 3 & 4 & 0 & 1 & 2 & 3 & 4 & 0 & 1 & 2 & 3 & 4 & 0 & 1 & 2 & 3 & 4 \\
\hline Conbercept group & 0 & 6 & 28 & 14 & 10 & 26 & 10 & 2 & 0 & 32 & 8 & 0 & 0 & 0 & 44 & 4 & 0 & 0 & 0 & 38 & 10 & 0 & 0 & 4 & 6 & 31 & 7 & 0 \\
\hline 5-Fu group & 0 & 4 & 32 & 12 & 4 & 16 & 20 & 8 & 0 & 22 & 18 & 4 & 0 & 0 & 24 & 16 & 6 & 2 & 0 & 16 & 18 & 10 & 4 & 0 & 2 & 30 & 10 & 6 \\
\hline Mann-Whitney $U$ & \multicolumn{4}{|l|}{1144} & \multicolumn{5}{|c|}{720} & \multicolumn{4}{|l|}{776} & \multicolumn{5}{|c|}{656} & \multicolumn{5}{|c|}{554} & \multicolumn{5}{|c|}{792} \\
\hline$p$ & \multicolumn{4}{|l|}{0.945} & \multicolumn{5}{|c|}{$0.001^{*}$} & \multicolumn{4}{|l|}{$0.002^{*}$} & \multicolumn{5}{|c|}{$0.000^{*}$} & \multicolumn{5}{|c|}{$0.000^{*}$} & \multicolumn{4}{|c|}{$0.002 *$} & \\
\hline
\end{tabular}

$* p<0.05$

Table 4 Recurrence of pre-1stinjection and post-3rd-injection 6 months in both the groups (case)

\begin{tabular}{|c|c|c|c|c|c|c|c|c|}
\hline \multirow[t]{2}{*}{ Group } & \multicolumn{4}{|c|}{ Pre-1st-injection } & \multicolumn{4}{|c|}{ Post-3rd-injection 6 months } \\
\hline & I & II & III & IV & I & II & III & IV \\
\hline Conbercept group & 0 & 44 & 4 & 0 & 10 & 31 & 7 & 0 \\
\hline 5-Fu group & 0 & 42 & 6 & 0 & 2 & 30 & 10 & 6 \\
\hline Mann-Whitney $U$ & \multicolumn{4}{|c|}{1104} & \multicolumn{4}{|l|}{796} \\
\hline$p$ & \multicolumn{4}{|c|}{0.506} & \multicolumn{4}{|l|}{$0.002 *$} \\
\hline
\end{tabular}

Table 5 Subgroup analysis of recurrent rate on post-3rd-injection 6 months (case)

\begin{tabular}{|c|c|c|c|c|c|c|c|c|}
\hline & \multicolumn{3}{|c|}{ Conbercept group } & \multicolumn{3}{|l|}{ 5-Fu group } & \multirow[t]{2}{*}{$\mathrm{RR}$} & \multirow[t]{2}{*}{$\operatorname{ARR}(95 \% \mathrm{CI})$} \\
\hline & Recurrence & No recurrence & Total & Recurrence & No recurrence & Total & & \\
\hline Simple excision surgery & 0 & 18 & 18 & 4 & 16 & 20 & 0 & $0.200(0.0248,0.375)$ \\
\hline Conjunctiva autograft surgery & 0 & 30 & 30 & 2 & 26 & 28 & 0 & $0.0714(-0.0238,0.169)$ \\
\hline Total & 0 & 48 & 48 & 6 & 42 & 48 & 0 & $0.125^{*}(0.0314,0.219)$ \\
\hline
\end{tabular}

${ }^{*} p<0.05$

Table 6 Complications on the post-3rd-injection 6 months in both the groups (case)

\begin{tabular}{lllll}
\hline & Conbercept group & 5 -Fu group & $\chi^{2}$ & $p$ \\
\hline Corneal abrasion & 0 & 17 & 20.658 & $0.000^{*}$ \\
$\begin{array}{l}\text { Persistent } \\
\text { epithelial defect }\end{array}$ & 0 & 3 & 3.097 & 0.078 \\
$\begin{array}{l}\text { Subconjunctival } \\
\text { haemorrhage }\end{array}$ & 9 & 8 & 0.071 & 0.789 \\
$\begin{array}{l}\text { Aseptic scleritis } \\
\text { Infection }\end{array}$ & 0 & 0 & - & - \\
\hline
\end{tabular}

* $<<0.05$

The frequency of dosing was as follows. Lekhanont et al. [23] concluded that a single subconjunctival bevacizumab injection reduced conjunctival congestion, but the effect was limited and transient. Bayar et al. [24] thought that repeated bevacizumab injections could reduce the recurrent rate and the effect was significant in the 1st year after surgery. NavaCastaneda et al. [25] observed that the neovascularization area of the cornea and cornea-conjunctiva, and corneal turbidity area was significantly reduced after 15 days, and 1, 3, 6, and 12 months after three consecutive times subconjunctival bevacizumab injections. To summarise, our team chose three subconjunctival injections for a more lasting effect.

Dosing was as follows. Dosing was not uniform for antiVEGF drugs, most of which were in the range of $0.5-2.5 \mathrm{mg}$ [7, 20, 21]. Anti-VEGF drugs were shown to be safe for humans in this dose range. Therefore, the minimum dose of $0.5 \mathrm{mg} / 0.2 \mathrm{ml}$ was selected for observation in this study.

The effect of anti-VEGF monoclonal antibody, like bevacizumab and ranibizumab, for preventing recurrence after pterygium surgery is controversial [19, 26]. Conbercept exhibits potent anti-angiogenesis activity, and puissant anti-inflammation because of blocking all isoforms of VEGF-A, VEGF-B and PIGF, and a higher binding affinity than monoclonal antibody in vitro and in vivo [27].

This study showed that there were striking differences on the viewing times of the post-3rd injection between the two groups with respect to colour intensity, and the eyes in the conbercept group were lighter than the 5-Fu group. On post3rd injection 6 months, prominent disparities were found between the two groups with respect to pterygium morphology and recurrence, occurred in the conbercept group prior to the 5-Fu group. Further subgroup analysis showed that the recurrent rate of simple excision surgery in conbercept group 
was less than the 5-Fu group on post-3rd-injection 6 months. It was demonstrated that multiple subconjunctival conbercept injections reduced conjunctival congestion, fibroblast proliferation, and tissue relapse, which might be associated with the function of anti-PIGF on early post-operatively. The reason for this finding was that PIGF had the function of promoting inflammation and inducing angiogenesis through the PI3K/Akt signalling pathway [28]. Hence, multiple subconjunctival conbercept injections is an effective treatment in preventing pterygium recurrence after surgery.

This study found that corneal abrasion was not detected in the conbercept group, which was significantly less than the 5-Fu group (17 eyes). Moreover, there was no conspicuous discrepancy between the two groups with respect to subconjunctival haemorrhage and persistent epithelial defects. Therefore, multiple subconjunctival conbercept injections had fewer complications than 5-Fu and is a safe method for the prevention of pterygium recurrence after surgery.

In summary, multiple subconjunctival conbercept injections as an adjunct therapy for pterygium surgery is a safe, effective, and well-tolerated method. Although some results have been obtained in our study, we still have a lot of work to do in the future, such as increasing the clinical sample size, extending the observation time, comparing the validity with other anti-VEGF drugs, and exploring the relevant basic research on the recurrence of pterygium after surgery.

\section{Summary}

\section{What was known before}

- Currently, the main treatment strategy of pterygium is surgery; however, the problem of post-operative recurrence has not been resolved.

- Therefore, it is well-known that there are several common methods, such as adjuvant anti-metabolic treatments, including mitomycin, 5-fluorouracil (5-Fu), and corticosteroids, to prevent recurrences.

- An increased incidence of adverse effects following anti-metabolic treatment has been observed, including corneal abrasions, corneal epithelial defects, subconjunctival haemorrhage, aseptic scleritis, and infections.

- Therefore, a safe and effective agent is urgently needed to prevent recurrences after pterygium surgery.

\section{What this study adds}

- Evaluate the safety and efficacy of multiple subconjunctival injections of conbercept for pterygium patients after surgery
Acknowledgements We thank X Fu, Q Xiong, S Cheng, YJ Wang, L Yang, W Zhang for helping us on technical support. We also thank $\mathrm{XJ}$ Cai, $\mathrm{H}$ Luo, and $\mathrm{M}$ Yan for introducing us some pterygium patients. All of them above were from the Department of Ophthalmology, Zhongnan Hospital of Wuhan University.

\section{Compliance with ethical standards}

Conflict of interest The authors declare that they have no conflict of interest.

Publisher's note Springer Nature remains neutral with regard to jurisdictional claims in published maps and institutional affiliations.

\section{References}

1. Nuzzi R, Tridico F. How to minimize pterygium recurrence rates: clinical perspectives. Clin Ophthalmol. 2018;12:2347-2362. https://doi.org/10.2147/OPTH.S186543

2. Wu KY, Lai YH, Yang YC, Wu WC, Hong SJ. 5-Fluorouracilinduced apoptosis changes in cultured corneal epithelial cells. J Ocul Pharm Ther. 2016;32:155-162. https://doi.org/10.1089/jop. 2015.0109

3. Bianchi E, Scarinci F, Grande C, Plateroti R, Plateroti P, Plateroti $\mathrm{AM}$, et al. Immunohistochemical profile of VEGF, TGF- $\beta$ and PGE2 in human pterygium and normal conjunctiva: experimental study and review of the literature. Int J Immunopathol Pharm. 2012;25:607-615. https://doi.org/10.1177/039463201202500307

4. Uyeturk U, Gucuk A, Firat T, Kemahli E, Kukner A, Ozyalvacli ME. Effect of mitomycin, Bevacizumab, and 5-fluorouracil to hibit urethral fibrosis in a rabbit model. J Endourol. 2014;28:1363-1367. https://doi.org/10.1089/end.2014.0420

5. Lytvynchuk L, Sergienko A, Lavrenchuk G, Petrovski G. Antiproliferative, apoptotic, and autophagic activity of ranibizumab, bevacizumab, pegaptanib, and aflibercept on fibroblasts: implication for choroidal neovascularization. J Ophthalmol. 2015;2015:934963 https://doi.org/10.1155/2015/934963

6. Wu Z, Zhou P, Li X, Wang H, Luo D, Qiao H, et al. Structural characterization of a recombinant fusion protein by instrumental analysis and molecular modeling. PLoS ONE. 2013;8:e57642 https://doi.org/10.1371/journal.pone.0057642

7. Bekibele CO, Sarimiye TF, Ogundipe A, Olaniyan S. 5-Fluorouracil vs avastin as adjunct to conjunctival autograft in the surgical treatment of pterygium. Eye(Lond). 2016;30:515-521. https://doi.org/10. 1038/eye.2016.29

8. Prabhasawat P, Barton K, Burkett G, Tseng SC. Comparison of conjunctival autografts, amniotic membrane grafts, and primary closure for pterygium excision. Ophthalmology. 1997;104:974-985.

9. Tan DT, Chee SP, Dear KB, Lim AS. Effect of pterygium morphology on pterygium recurrence in a controlled trial comparing conjunctival autografting with bare sclera excision. Arch Ophthalmol. 1997;115:1235-40.

10. Teng CC, Patel NN, Jacobson L. Effect of subconjunctival bevacizumab on primary pterygium. Cornea 2009;28:468-70. https:// doi.org/10.1097/ICO.0b013e31818d382d

11. Campagna G, Adams M, Wang L, Khandelwal S, Al-Mohtaseb Z. Comparison of pterygium recurrence rates among different races and ethnicities after primary pterygium excision by surgeons in training. Cornea. 2018;37:199-204. 10.1097/ICO. 0000000000001453

12. Mauro J, Foster CS. Pterygia: pathogenesis and the role of subconjunctival bevacizumab in treatment. Semin Ophthalmol. 2009;24:130-4. https://doi.org/10.1080/08820530902801106 
13. Adamis AP, Shima DT. The role of vascular endothelial growth factor in ocular health and disease. Retina. 2005;25:111-8.

14. Kim KW, Park SH, Wee SW, Kim JC. Overexpression of angiogenin in pterygium body fibroblasts and its association with proliferative potency. Invest Ophthalmol Vis Sci. 2013;54:6355-62. https://doi.org/10.1167/iovs.13-12141

15. Chen JJ, Lan YQ, Wu GF, Huang QT, Zeng YT. Study on fibroblasts in vasculogenic mimicry of pterygium induced by VEGF. Chin J Ophthalmol Med (Electron Ed). 2017;7:12-17. (Chinese)

16. Zheng LY. Clinical research of the expression of VEGF in recurrent pterygium. Med Innov China. 2016;13:39-42. (Chinese)

17. Wu PC, Kuo HK, Tai MH, Shin SJ. Topical Bevacizumab eyedrops for limbal-conjunctival neovascularization in impending recurrent pterygium. Cornea. 2009;28:103-4. https://doi.org/10. 1097/ICO.0b013e3181822615

18. Motarjemizadeh Q, Aidenloo NS, Sepehri S. A comparative study of different concentrations of topical Bevacizumab on the recurrence rate of excised primary pterygium: a short-term follow-up study. Int Ophthalmol. 2016;36:63-71. https://doi.org/10.1007/ s10792-015-0076-4

19. Mohamed TA, Soliman W, Fathalla AM, Refaie EI. A. Effect of single subconjunctival injection of bevacizumab on primary pterygium: clinical, histopathological and immunohistochemical study. Int J Ophthalmol. 2018;11:797-801. https://doi.org/10. 18240/ijo.2018.05.13

20. Alsmman AH, Radwan G, Abozaid MA, Mohammed UA, Abd Elhaleim NG. Preoperative subconjunctival combined injection of Bevacizumab and mitomycin $\mathrm{C}$ before the surgical excision of primary pterygium: clinical and histological results. Clin Ophthalmol. 2017;11:493-501. https://doi.org/10.2147/OPTH.S127700

21. Nuzzi R, Tridico F. Efficacy of subconjunctival bevacizumab injections before and after surgical excision in preventing pterygium recurrence. J Ophthalmol. 2017;2017:6824670 https:// doi.org/10.1155/2017/6824670

22. Masoumpour MB, Nowroozzadeh MH, Razeghinejad MR. Current and future techniques in wound healing modulation after glaucoma filtering surgeries. Open Ophthalmol J. 2016;10:68-85. https://doi.org/10.2174/1874364101610010068

23. Lekhanont K, Patarakittam T, Thongphiew P, Suwan-apichon O, Hanutsaha P. Randomized controlled trial of subconjunctival bevacizumab injection in impending recurrent pterygium: a pilot study. Cornea. 2012;31:155-61. https://doi.org/10.1097/ICO. 0b013e3182151e0e

24. Bayar SA, Kucukerdonmez C, Oner O, Akova YA. Subconjunctival bevacizumab in the impending recurrent pterygia. Int Ophthalmol. 2014;34:541-7. https://doi.org/10.1007/s10792-013-9852-1

25. Nava-Castaneda A, Ulloa-Orozco I, Garnica-Hayashi L, HernandezOrgaz J, Jimenez-Martinez MC, Garfias Y. Triple subconjunctival Bevacizumab injection for early corneal recurrent pterygium: oneyear follow-up. J Ocul Pharm Ther. 2015;31:106-113. https://doi. org/10.1089/jop.2014.0060

26. Hurmeric V, Vaddavalli P, Galor A, Perez VL, Roman JS, Yoo SH. Single and multiple injections of subconjunctival Ranibizumab for early, recurrent pterygium. Clin Ophthalmol. 2013;7:467-73. https://doi.org/10.2147/OPTH.S40400

27. Wang F, Bai Y, Yu W, Han N, Huang L, Zhao M, et al. Antiangiogenic effect of KH902 on retinal neovascularization. Graefes Arch Clin Exp Ohthalmol. 2013;251:2131-9. https://doi.org/10. 1007/s00417-013-2392-6

28. Zhou Y, Tu C, Zhao Y, Liu H, Zhang S. Placental growth factor enhances angiogenesis in human intestinal microvascular endothelial cells via PI3K/Akt pathway: potential implications of inflammation bowel disease. Biochem Biophys Res Commun. 2016;470:967-74. https://doi.org/10.1016/j.bbrc.2016.01.073 